\title{
Extraction Method for the Determination of Atrazine, Deethylatrazine, and Deisopropylatrazine in Agricultural Soil Using Factorial Design
}

\author{
Maristela F. Amadori, ${ }^{a, b}$ Gilcélia A. Cordeiro, ${ }^{c}$ Caio C. Rebouças, ${ }^{a}$ \\ Patricio G. Peralta-Zamora, ${ }^{a}$ Marco T. Grassi, ${ }^{a}$ and Gilberto Abate ${ }^{*, a}$ \\ ${ }^{a}$ Departamento de Química, Centro Politécnico,Universidade Federal do Paraná, \\ CP 19081, 81531-990 Curitiba-PR, Brazil \\ ${ }^{b}$ Universidade Tecnológica Federal do Paraná, Campus de Pato Branco, \\ CP 571, 85503-390 Pato Branco-PR, Brazil
}

\begin{abstract}
'Laboratório de Estudos Interdisciplinares do Meio Ambiente, Universidade Federal da Integração Latino-Americana, Av. Tancredo Neves, 6731 Bloco 4, CP 2044, 85867-970 Foz do Iguaçu-PR, Brazil
\end{abstract}

\begin{abstract}
Neste trabalho foi proposto um procedimento para a extração do herbicida atrazina (AT) e dos principais metabólitos desetil-atrazina (DEA) e desisopropil-atrazina (DIA) de uma amostra de latossolo vermelho proveniente da região sudoeste do estado do Paraná no Brasil, onde a AT está entre os herbicidas mais amplamente utilizados. Foi conduzida uma comparação usando extração por agitação e por ultrassom, sendo obtido um procedimento de extração simples e rápido, seguido pela quantificação por cromatografia em fase líquida de alta eficiência. Cabe ressaltar que foi utilizado um estudo por planejamento fatorial, o qual foi decisivo para determinar as melhores condições de extração por agitação. Foram obtidos percentuais de recuperação e desvios padrão relativos adequados, para amostras de solo de três diferentes profundidades, o que sugere a possibilidade de empregar o método de extração proposto para a quantificação de AT, DEA e DIA em amostras de latossolo vermelho.
\end{abstract}

An optimization procedure for the extraction of the herbicide atrazine (AT), and the main degradation products deethylatrazine (DEA) and deisopropylatrazine (DIA) from an oxisol soil sample was carried out, for a soil from the Southwest of Paraná State in Brazil, where AT is among the most largely employed herbicide. A comparison between shaking and ultrasound extraction was performed, to define a simple and fast extraction procedure, followed by the quantification using high performance liquid chromatography. It is important to inform that a factorial planning was employed, that was very important to define the best conditions of extraction by shaking. Appropriate recovery values were observed using soil samples from three different depths, as well as the relative standard deviation, suggesting the possibility to employ the proposed extraction method for quantification of AT, DEA and DIA in oxisol samples.

Keywords: triazines, degradation products, oxisol, HPLC

\section{Introduction}

Nowadays, triazines are the most commercialized herbicides worldwide. In Brazil, atrazine (AT, 2-chloro4-(ethylamino)-6-(isopropylamino)-s-triazine) is one of the most largely used herbicides, mainly in corn, cotton and sugar-cane cultures. According to Martinazzo et al., ${ }^{1}$ between 2009 and 2010, an estimate of 9,750 ton of AT was utilized in Brazil, considering the lowest recommended

*e-mail: gilbertoabate@ufpr.br dose of $0.75 \mathrm{~kg} \mathrm{ha}^{-1}$. Because of this intense use and the physicochemical properties, AT may be a potential contaminant of soils as well as surface and groundwaters. Furthermore, the mineral and organic matter composition of the soils is a relevant aspect related to the retention in soils and consequently the surface and groundwater contamination, being reported that the organic matter has a key role in the sorption of AT in soils..$^{2-4}$ In spite of this, AT and the metabolites, deethylatrazine (DEA, 2-amino4-chloro-6-isopropylamino-s-triazine), deisopropylatrazine (DIA, 2-amino-4-chloro-6-ethylamino-s-triazine) and 
hydroxyatrazine (HA, 2-hydroxy-4-ethylamino-6isopropylamino-s-triazine), have been detected in surface and groundwaters. ${ }^{5} \mathrm{HA}$ presents lower mobility in soils in comparison with DEA and DIA, and for this reason greater attention has been given to these two metabolites and the parent herbicide. ${ }^{6-9}$ According to Potter et al., ${ }^{6}$ the monitoring of shallow groundwater in four corn crops in Florida State, USA showed that DEA, DIA and the parent herbicide are the main residues, with DEA accounting for more than half of all residues in most samples. Because of the great importance of this subject, regression models were developed to evaluate groundwater in agricultural areas of USA for AT and DEA, using 1298 wells and explanatory variables related to the source of AT and other aspects of transport and fate of these contaminants in the subsurface. ${ }^{10}$ Thus, based on the excessive use, and the lixiviation process of AT, DEA and DIA, the prevention and knowledge of leaching process based on the soil characteristics and the correct application are essential, in order to minimize the groundwater contamination. Therefore the understanding of the sorption behavior in soils is a fundamental aspect for the foresight of the organic pollutant release, ${ }^{11}$ which requires appropriate and validated extraction and quantification methods.

The technique of gas chromatography (GC) may be employed for triazine determination in soils, providing small limits of quantification. ${ }^{12}$ Nevertheless, the determination of the more polar and low-volatility compounds such as hydroxylated triazines, involves a derivatization step, and the soil extracts commonly are in aqueous medium. For these reasons, high performance liquid chromatography (HPLC) has been the analytical technique most largely employed for triazines determination in soils. ${ }^{1-3,5,8,11,13-17}$

The quality of the analytical data is mostly dependent on the sample preparation, especially for the procedures of extraction and cleanup, ${ }^{18}$ and as a result, this is a critical step for the determination of any contaminant in soil samples. For that reason, several different approaches have been proposed for the extraction and cleanup of triazines in soils. A traditional and low cost method that can be used for triazine extraction from soils is soxhlet, that yields efficient extraction, but it is a time and solvent consuming method. ${ }^{12,19}$ Because of this, green extraction methods have been proposed, including ultrasonic solvent extraction (USE), ${ }^{14,19}$ microwave assisted extraction (MAE), ${ }^{15,16}$ supercritical fluid extraction (SFE), ${ }^{20}$ extraction of the analytes after the shaking of the sample in the presence of an appropriate solvent, followed by solid phase extraction (SPE), ${ }^{17}$ headspace solid-phase microextraction (HS-SPME), ${ }^{21}$ pressurized liquid extraction (PLE), 1,12,13,22 besides the development of other miniaturized methods as reported in the literature. ${ }^{14}$ These methods usually present appropriate results, however some authors have used a less expensive extraction method, based on a simple shaking with solvents of adequate polarity like acetonitrile or methanol and water, providing acceptable recovery values for the extraction of triazine herbicides from soils; ${ }^{5,8,19}$ nevertheless, the extraction time is often a drawback, for instance, Mahía et al., ${ }^{5}$ and Delgado-Moreno et al., ${ }^{19}$ employed $24 \mathrm{~h}$ as extraction time. As a result, chemometric studies have been used in order to save time and improve the correlation of the different factors involved in the extraction step for triazines and other pesticides. ${ }^{19,20,23}$

Although the sorption of atrazine DEA and DIA is moderate in soils, the organic matter (OM) seems to be the main factor influencing the mobility of triazines, ${ }^{3,11}$ and not only the OM content, but also its composition plays an important role in the atrazine sorption in soils. ${ }^{24}$ Atrazine can be mineralized by biological activity or immobilized by physicochemical processes, generating non-extractable residues, ${ }^{5,22}$ therefore, the conventional extraction methods for quantification of atrazine in soils may be inappropriate. ${ }^{5}$ As a result, the extraction method may be considered the most relevant step for quantification of atrazine and other triazines in soils; hence, it is of prime importance the optimization of the extraction parameters. ${ }^{23}$ The purpose of the present study was to investigate the best conditions for the extraction of AT, DEA and DIA from an oxisol sample, rich in clay fraction and organic matter, using a simple and low cost method optimized by a $2^{3}$ factorial design. The soil under examination is from an important agricultural area in Pato Branco City, Paraná State, Brazil, and no studies about extraction methods of atrazine and these relevant degradation products were made for the oxisol samples, until this moment. Moreover, this study will be valid in the near future for an evaluation concerning the behavior of atrazine and the possible evolution of DEA and DIA in this important class of soil from a maize crop.

\section{Experimental}

\section{Materials, equipments and reagents}

The analytical standard of the herbicide AT was supplied by Sigma-Aldrich (98.9\%) and the degradation products DEA (95.5\%) and DIA (97.0\%) were acquired from Dr. Ehrenstorfer GmbH. The stock solutions of each compound were prepared in methanol at $1000 \mathrm{mg} \mathrm{L}^{-1}$ and stored in a freezer $\left(-18^{\circ} \mathrm{C}\right)$. Table 1 shows the structures 
Table 1. Structures and some physicochemical parameters ${ }^{25}$ of the analytes

\begin{tabular}{|c|c|c|c|}
\hline Parameter & Atrazine & Deethylatrazine & Deisopropylatrazine \\
\hline Structure & & $\mathrm{NH}-\mathrm{CH}-$ & $\mathrm{C}_{2} \mathrm{H}_{5}-\mathrm{HN}^{\prime}$ \\
\hline Molar mass / $\left(\mathrm{g} \mathrm{mol}^{-1}\right)$ & 215.68 & 187.68 & 173.68 \\
\hline Water solubility / $\left(\mathrm{mg} \mathrm{L}^{-1}\right)$ & 33 & 3200 & 670 \\
\hline $\mathrm{p} K_{\mathrm{a}}$ & $1.68-1.71$ & $1.30-1.65$ & $1.30-1.58$ \\
\hline $\log K_{\mathrm{OW}}$ & $2.20-2.70$ & 1.52 & 1.13 \\
\hline
\end{tabular}

of the compounds, as well as some physicochemical properties. Methanol and acetonitrile (HPLC grade) were supplied by Carlo Erba. The water used in all experiments was obtained by reverse osmosis system, model Q842-210, from Quimis, followed by purification using the equipment model Simplicity UV, from Millipore, equipped with an UV lamp, in order to obtain ultrapure water (resistivity of 18 $\mathrm{M} \Omega \mathrm{cm}$ ). A Hanna potentiometer, model $\mathrm{pH} 21$ coupled to an $\mathrm{Ag} / \mathrm{AgCl}$ combined glass electrode was used to measure all the $\mathrm{pH}$ values. The additional reagents employed in the present work were of analytical grade and supplied by Merck, Carlo Erba, J.T. Baker or similar quality. All glassware was initially kept for $24 \mathrm{~h}$ in $2.5 \%$ (v/v) alkaline detergent solution (Detertec) and then washed with water from reverse osmosis, ultrapure water and dried in a dust free environment. An ultrasound bath (Unique), with frequency of $25 \mathrm{kHz}$ and $135 \mathrm{~W}$ of power was employed, as well as an orbital shaker from Evlab (Standard EV07), at $70 \mathrm{rpm}$ for the shaking extractions.

\section{HPLC and chromatographic conditions}

An HPLC equipment from Varian (920-LC) coupled to a photodiode array detector (CP225) was employed, and the acquisition of the signals was made in $220 \mathrm{~nm}$ using the software Galaxie version 1.9. A volume of $25 \mu \mathrm{L}$ was employed in all determinations by using an automatic injector. An octadecylsilane (C18) column, ACE $(5 \mu \mathrm{m}, 4.6 \mathrm{~mm} \times 100 \mathrm{~mm})$ was used, connected to a C18 guard column, ACE ( $5 \mu \mathrm{m}, 4.6 \mathrm{~mm})$. The mobile phase previously filtered in $0.45 \mu \mathrm{m}$ PTFE membrane (Millipore) was constituted of deionized water (60\%) and acetonitrile (40\%) using isocratic mode, at a flow rate of $1.0 \mathrm{~mL} \mathrm{~min}^{-1}$ and degassed just before the use in the HPLC system. The analytical curves were obtained with five standards, containing AT, DEA and DIA between the concentrations of 5.00 and $1000 \mu \mathrm{g} \mathrm{L}^{-1}$. All the samples were filtered through disposable $0.45 \mu \mathrm{m}$ PTFE membrane from Millipore, with $25 \mathrm{~mm}$ of diameter, before the HPLC analysis.

Soil sample

The soil sample, classified as oxisol, was collected in an experimental area of Instituto Agronômico do Paraná (IAPAR) in Pato Branco City located in the Southwest of the Paraná State, Brazil, $430 \mathrm{~km}$ distant from the capital, Curitiba. This experimental area has no history of herbicides or other chemical applications, but the soil sample is representative of the agricultural region, mainly maize crop. The samples were collected at depths of 0-10, 10-30 and $30-50 \mathrm{~cm}$ from ten different points in an area of one hectare, and mixed to compose a single sample, for each depth. The sample was air-dried for three days, gently ground to pass through a $2 \mathrm{~mm}$ sieve and stored in a desiccator to be employed in the experiments. A previous characterization of the sample was made, based on the traditional methods. The pipette method was used for the determination of the clay, silt and sand content. The percentage of organic matter was determined by the Walkley-Black method, while the carbon content was determined by the combustion method using the equipment from Perkin Elmer, model $2400 \mathrm{CHN}$. The cation exchange capacity (CEC) was determined based on the $\mathrm{Al}^{3+}$, $\mathrm{Ca}^{2+}$, and $\mathrm{Mg}^{2+}$ contents, extracted by a $1.0 \mathrm{~mol} \mathrm{~L}^{-1} \mathrm{KCl}$ solution. The main results of the characteristics of this soil are shown in Table 2.

\section{Extraction procedure}

A mass of $2.0 \mathrm{~g} \mathrm{(} \pm 0.1 \mathrm{mg}$ ) of the soil was weighted in $25 \mathrm{~mL}$ glass flasks. One milliliter of a solution containing AT, DEA and DIA was added in order to obtain a content of $2.50 \mathrm{mg} \mathrm{kg}^{-1}$ for each analyte, being the slurry homogenized and maintained for $72 \mathrm{~h}$ until dry. A preliminary experiment was made for a comparative study between shaking extraction (SE) and ultrasonic 
Table 2. Main characteristics of the oxisol sample from the experimental area of IAPAR, Pato Branco City, southwest of Paraná State

\begin{tabular}{lccc}
\hline \multirow{2}{*}{ Parameter } & \multicolumn{3}{c}{ Results $^{\mathrm{a}}$} \\
\cline { 2 - 4 } & $0-10 \mathrm{~cm}$ & $10-30 \mathrm{~cm}$ & $30-50 \mathrm{~cm}$ \\
\hline Clay / \% & b & $76 \pm 1$ & $74 \pm 1$ \\
Silt / \% & b & $21.2 \pm 1$ & $23.1 \pm 2$ \\
Sand / \% & $22.4 \pm 2$ & $2.8 \pm 0.2$ & $2.9 \pm 0.1$ \\
Organic Matter / \% & $4.2 \pm 0.2$ & $3.4 \pm 0.8$ & $3.6 \pm 0.5$ \\
pH $\left(0.01 \mathrm{~mol} \mathrm{~L}^{-1} \mathrm{CaCl}_{2}\right.$ & $5.0 \pm 0.3$ & $4.7 \pm 0.5$ & $4.9 \pm 0.5$ \\
solution) & & & \\
$\mathrm{CEC} /$ & $5.2 \pm 0.4$ & $4.0 \pm 0.4$ & $4.0 \pm 0.4$ \\
(cmol $\left._{\mathrm{c}}^{\mathrm{b}} \mathrm{kg}^{-1}\right)$ & & & \\
$\mathrm{C} / \%$ & 2.8 & 2.3 & 2.1 \\
\hline
\end{tabular}

${ }^{a}$ Results of triplicate experiments, except carbon (duplicate); ${ }^{\text {the results of }}$ these parameters are in good agreement with the data reported by Balena et al. ${ }^{26}$ for the same region, for the depth of $0-20 \mathrm{~cm}$.

extraction (UE), using $3.0 \mathrm{~mL}$ of an extraction solvent composed of $80 \%$ acetonitrile and $20 \%$ ultrapure water for both methods. For SE the samples were kept under shaking with the extracting solution for $1 \mathrm{~h}$ at $70 \mathrm{rpm}$, the suspensions were centrifuged and the supernatant phases reserved. This step was carried out three times, and the respective supernatant phases were combined. For UE the samples were sonicated for 10,20 and $30 \mathrm{~min}$, centrifuged and the supernatants combined similarly as for SE. The extracts were transferred to $10.0 \mathrm{~mL}$ volumetric flasks, filtered using $0.45 \mu \mathrm{m}$ PTFE membranes and diluted with ultrapure water $(1: 1, \mathrm{v} / \mathrm{v})$ before the HPLC determination. Besides the blank experiment, a test consisting of AT, DEA and DIA at concentrations of $5.00 \mu \mathrm{g} \mathrm{L}^{-1}$ each one, and other test using the same three compounds at concentrations of $10.00 \mu \mathrm{g} \mathrm{L}-1$ each one were made, in the presence of the soil extract, and the determinations were carried out by HPLC.

A second set of experiments was done using only SE, since better recoveries were verified with this method of extraction. In these experiments, the same mass of soil from each depth was mixed to obtain one sample, and $2.0 \mathrm{~g}( \pm 0.1 \mathrm{mg})$ of this soil sample used for SE. Three factors were evaluated using a $2^{3}$ factorial design: (i) time of shaking 30, 60 and $90 \mathrm{~min}$; (ii) number of extractions one, two and three extractions and (iii) the composition of the extracting solution acetonitrile:water (ACN:water) 60:40, 80:20 and pure ACN. The experiments were done in duplicate, except the central point (two extractions, 60 min and ACN:water 80:20) made in triplicate. After the establishment of the best extraction conditions based on the recovery values, two replicates $(n=5)$ were carried out using $2.0 \mathrm{~g}( \pm 0.1 \mathrm{mg})$ of the same soil sample, previously spiked with AT, DEA and DIA at $2500 \mu \mathrm{g} \mathrm{kg}^{-1}$. The same extraction process was performed, but using AT, DIA and DEA at 500, 2000 and $5000 \mu \mathrm{g} \mathrm{kg}^{-1}(n=3)$.

Finally, additional experiments were made using similar conditions, but the flasks were kept in the dark in a refrigerator at $4{ }^{\circ} \mathrm{C}$ for $15,30,45$ and 60 days, and then the optimized extraction procedure was employed. Blank experiments were done in parallel for each extraction time.

\section{Results and Discussion}

\section{HPLC quantification}

The mobile phase composed of acetonitrile:water (40:60) provided the determination of DIA, DEA and AT using the isocratic mode at a flow rate of $1.0 \mathrm{~mL} \mathrm{~min}^{-1}$. This condition with the $\mathrm{C} 18$ column that was employed, allowed short chromatographic runs with retention times (min) of 1.61 (DIA), 2.01 (DEA) and 5.35 (AT). These low retention times for DIA and DEA are due to their high polarity with low $\log K_{\text {OW }}$ values (Table 1), but appropriate resolution between the DIA and DEA peaks was obtained, that was a condition suitable to save solvent and time in comparison with the literature, ${ }^{5,13,27}$ including the DEA and DIA determination. The retention times were comparable with the literature, ${ }^{17}$ that obtained near 5.4 min for the elution of AT, but using ultra high performance liquid chromatography and gradient elution. The analytical curves for a concentration range between 5.00 and $1000 \mu \mathrm{g} \mathrm{L}^{-1}$, showed $r$ values higher than 0.9990 in different days of work, and slope values $\left(\mathrm{L} \mathrm{\mu} \mathrm{g}^{-1}\right)$ of $2.8 \times 10^{-3}$ (DEA), $3.2 \times 10^{-3}$ (AT) and $3.7 \times 10^{-3}$ (DIA). The approximate limit of detection (LOD) was $0.5 \mu \mathrm{g} \mathrm{L}^{-1}$ (DIA and DEA), and $0.9 \mu \mathrm{g} \mathrm{L} \mathrm{L}^{-1}$ (AT), while for the limit of quantification (LOQ) the values of $1.6 \mu \mathrm{g} \mathrm{L}^{-1}$ (DIA and DEA) and $2.9 \mu \mathrm{g} \mathrm{L}^{-1}$ (AT), were observed. In spite of the low concentration of $5.00 \mu \mathrm{g} \mathrm{L}^{-1}$, considering the use of photodiode array detector, it is important to notice that a maximum relative standard deviation (RSD) value of the peak areas (interday) for this concentration was $16 \%$ (AT), suggesting this value as the LOQ. Figure 1 shows the chromatograms of the soil extracts spiked with 5.00 and $10.00 \mu \mathrm{g} \mathrm{L}^{-1}$ of each analyte, and the blank test.

The spike of the soil extracts was made in order to verify the possibility to quantify low concentrations of the analytes that is limited by the analytical technique. According to Figure 1, one can infer that the quantification of AT, DIA and DEA is feasible in concentrations higher than $5.00 \mu \mathrm{g} \mathrm{L}^{-1}$ and no clean up was necessary, based on the blank test. It is important to notice that one kind of sample was studied (oxisol from Pato Branco City), but several experiments were made, in order to conclude that no clean up would be required. This is consistent with 


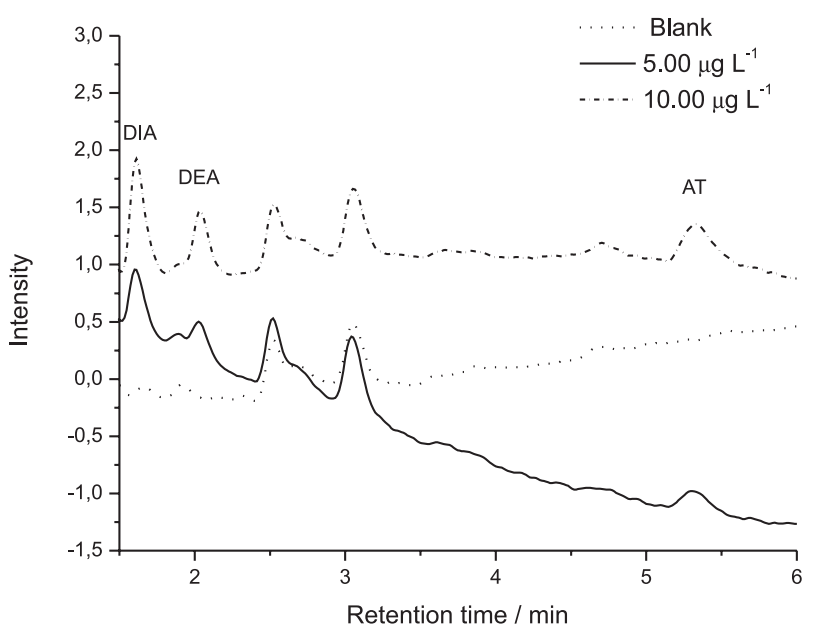

Figure 1. Chromatograms of atrazine (AT), deisopropylatrazine (DIA) and deethylatrazine (DEA), at concentrations of 5.00 and $10.00 \mu \mathrm{g} \mathrm{L}^{-1}$ and the blank test, all in the presence of the soil extract.

the behavior of the baseline, in spite of the relatively high organic matter content, between 3.4 and $4.2 \%$ (Table 2), that probably is responsible by the two peaks in $t_{\mathrm{R}}$ of approximately 2.5 and $3.1 \mathrm{~min}$, which were always present in the blank extracts. Therefore it was adopted the LOQ value of $5.00 \mu \mathrm{g} \mathrm{L}^{-1}$, since this concentration yields low RSD of the peak areas, and also is in good agreement with the values usually reported in the literature..$^{2,27}$ Consequently, based on the mass of soil and in the steps of extraction and dilution, the LOQ in the soil sample was estimated at $50 \mu \mathrm{g} \mathrm{kg}^{-1}$.

\section{Comparison between shaking extraction (SE) and ultrasonic extraction (UE)}

A preliminary experiment was made in order to compare the shaking extraction (SE) and ultrasonic extraction (UE). It was used the content of $2500 \mu \mathrm{g} \mathrm{kg}^{-1}$ of each analyte and the composition of the extracting solution of $80 \%$ acetonitrile and $20 \%$ ultrapure water, and the recovery results are shown in Figure 2.

According to Figure 2, higher percent recoveries were verified by using SE in comparison with UE for all experiments. Results between $68.2 \%$ for AT $(10-30 \mathrm{~cm})$ and $95.5 \%$ for DEA $(0-10 \mathrm{~cm})$ were observed for SE, whereas for UE, the percent recoveries were from $45.8 \%$ for AT $(10-30 \mathrm{~cm})$ and $84.4 \%$ for DEA $(0-10 \mathrm{~cm})$. Atrazine presented the lower recovery for the three depths, not only for SE, but also for UE, probably due to its lower solubility in water and higher $\log K_{\text {Ow }}$ in comparison with DEA and DIA (Table 1). Because of the high organic matter $(\mathrm{OM})$ content, even for the layers of $10-30$ and $30-50 \mathrm{~cm}$, a higher interaction between AT and the organic matter could occur, explaining the lower recoveries, in spite of the

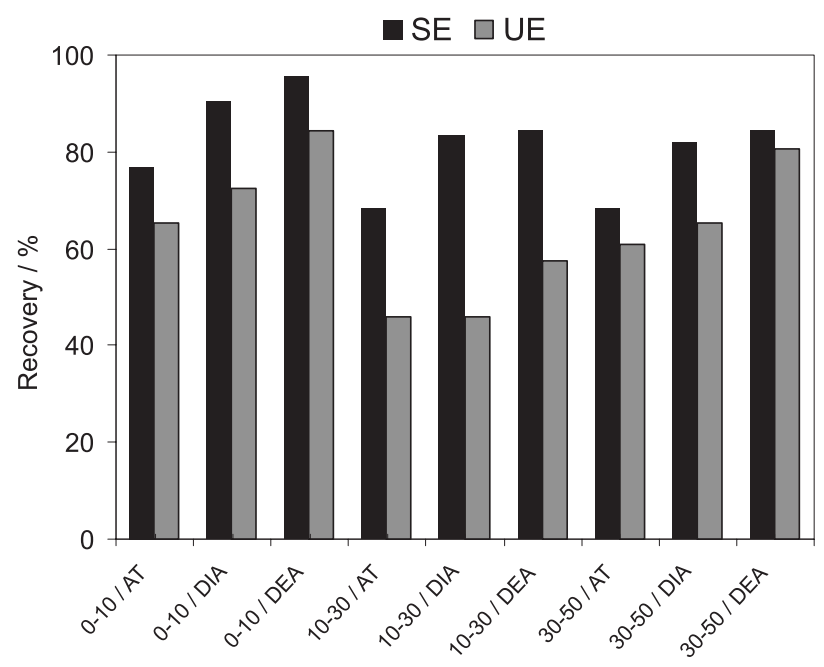

Figure 2. Recovery results for shaking extraction (SE) and ultrasonic extraction (UE) for atrazine (AT), deisopropylatrazine (DIA) and deethylatrazine (DEA) at initial content of $2500 \mu \mathrm{g} \mathrm{kg}^{-1}$, for the soil samples from depths of 0-10, 10-30 and 30-50 cm.

great acetonitrile percent in the extracting solution. On the contrary, Delgado-Moreno et al.,${ }^{19}$ employing methanol for extraction of four different triazines in soils, accomplished recoveries between 75 and $85 \%$ for SE and from 87 to $107 \%$ for UE, in both cases under the optimized conditions. In this work the clay content (34\%) and OM content (2.2\%) are relatively lower in comparison with the present study (Table 2) that could be a factor related to the better recovery values, due to the relevant role of clay and $\mathrm{OM}$ in the sorption process of triazine herbicides. ${ }^{2,3,24} \mathrm{Wu}$ et al., ${ }^{14}$ carried out a study using ultrasound for the extraction of five different triazines from two soil samples, and the authors reported recovery values from 82.6 to $92.0 \%$, suggesting an appropriate extraction method. In addition, the ultrasonic frequency and the power of ultrasound are two important parameters for this kind of extraction..$^{28} \mathrm{Wu}$ et al. ${ }^{14}$ used $40 \mathrm{kHz}$ and $80 \mathrm{~W}$ for frequency and power, respectively; and Delgado-Moreno et al. ${ }^{19}$ employed $200 \mathrm{~W}$ for power (frequency not mentioned), and state that ultrasonic extractions are more vigorous system in comparison with shaking providing higher recoveries. Notwithstanding, in the present study SE was more effective than UE, perhaps due to the values of $25 \mathrm{kHz}$ and $135 \mathrm{~W}$ that were employed; although common ultrasonic baths have been used for extractions of different analytes. ${ }^{29}$ Nevertheless, according to Santos and Capelo, ${ }^{28}$ this kind of extraction is not appropriate for analytical applications, yielding between 1 and $5 \mathrm{~W} \mathrm{~cm}^{-2}$ of irradiation power, and for this reason suitable probes have been proposed. It is important to have in mind, that these authors consider the ability of the method to promote the total extraction and not only the extraction of the bioavailable fraction. Based on the 
recovery results (Figure 2) the SE was chosen for the determination of the best conditions for extraction.

\section{Optimization of the shaking extraction (SE)}

In order to determine the best conditions for SE, a $2^{3}$ factorial design was carried out. The time of shaking, the number of extractions and the composition of the extracting solution were evaluated. Figure 3 shows the geometric interpretation of the factorial design.

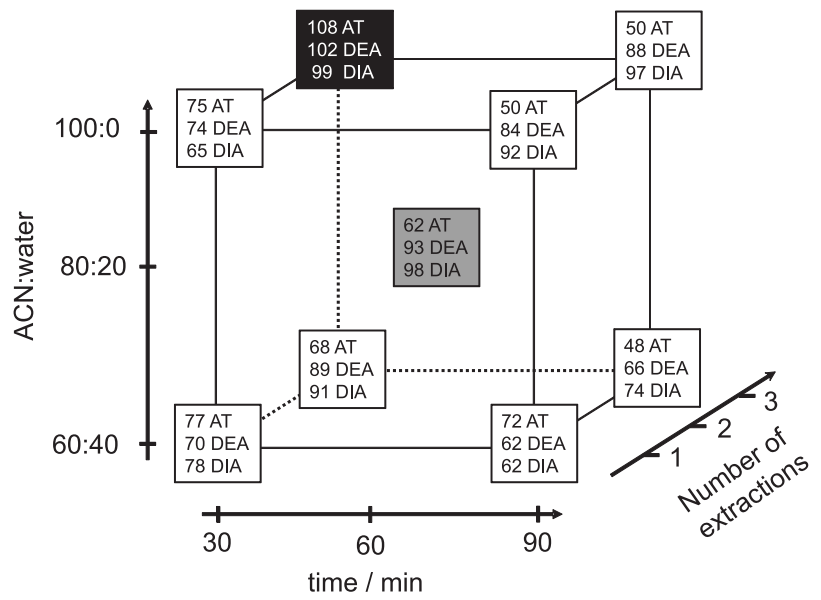

Figure 3. Geometric representation of the factorial design. Time of shaking: 30, 60 and $90 \mathrm{~min}$; number of extractions: one, two and three and the composition of the extracting solution of acetonitrile:water (ACN:water): 60:40, 80:20 and 100:0 (pure $\mathrm{ACN}$ ) The recovery results (\%) express the average of two experiments, except for the central point $(n=3)$.

According to Figure 3, AT showed the lowest recovery values in the most part of the experiments, whereas DEA was the compound more easily extracted. Considering a $95 \%$ confidence level, the central point exhibited recovery values of $62 \pm 3$ (AT), $93 \pm 9$ (DEA) and $98 \pm 8 \%$ (DIA). The use of three extractions presented the better results as expected, since the higher the number of extractions the better the recovery. As can be seen in Figure 3, different solvent compositions could be utilized for DIA and DEA, with satisfactory results, while for AT the best condition was with pure acetonitrile. Although higher times of extraction would be expected, the factorial design shown as result, the unexpected time of $30 \mathrm{~min}$ that is an attractive aspect, saving time of analysis. Briefly, the best extraction conditions were: three extractions, pure acetonitrile and 30 min of shaking. It must be kept in mind that the investigated conditions for the factorial design (time of extraction, ratio between acetonitrile and water and number of extractions) were based on the previous experiment, comparative between SE and UE. The composition of the solvent mixture was adopted based on the HPLC conditions that made use of 40:60 ACN:water. Furthermore, the literature suggests the use of extracting solutions based on acetonitrile and water or methanol and water in different ratios. ${ }^{18,23}$ Mahía et al. ${ }^{5}$ reported the use of methanol:water (70:30) for the extraction of AT, DIA, DEA and HA from soils with different characteristics. The authors did not present the recovery values, but a long time of $24 \mathrm{~h}$ was used as shaking time. Also using 24 h of shaking, DelgadoMoreno et al., ${ }^{19}$ showed recoveries between 75 and $85 \%$ for terbuthylazine, prometryn, simazine and cyanazine, using pure methanol. On the other hand, Kleinschmitt et al., ${ }^{30}$ employed $24 \mathrm{~h}$ as extraction time using pure methanol and verified between 30 and $35 \%$ of recovery for AT. Kookana et al., ${ }^{8}$ used ACN:water (90:10) and shaking extraction ( $2 \mathrm{~h}$ ) for AT, from different soil samples, and showed recovery of $106 \%$. Barchanska et al. ${ }^{17}$ reported an extraction study employing a mixture of $0.1 \mathrm{~mol} \mathrm{~L}^{-1}$ ACN:HCl (90:10), using only $30 \mathrm{~min}$ of shaking, before the use of SPE preconcentration. By means of this optimized solvent composition, the recovery of AT, DIA and DEA was 90, 78 and $60 \%$ respectively. Although no methanol was employed in the present study, these previous results from the literature suggest acetonitrile as the most appropriate solvent for the best recovery of triazines herbicides from soils, with lower time of extraction. Nevertheless, different factors may influence the extraction performance, especially organic matter and clay content that justify the importance of the previous determination of the better extraction parameters. Based on the best conditions of extraction, the results of 108 (AT), 102 (DIA) and 99\% (DEA) indicated an adequate accuracy for the total extraction of these compounds. It is important to notice, that the factorial design was an important tool to define the best conditions of extraction, especially the contact time of $30 \mathrm{~min}$, justifying its use in this kind of study.

\section{Application of the method}

The average values obtained in the best conditions for the extraction, presented in Figure 3 were carried out in duplicate. Thus, two different replicates $(n=5$, $95 \%$ confidence level), using the optimized conditions were performed in different days by two analysts, and the following recovery values $(\%)$ were achieved: (i) $\mathrm{AT}=99 \pm 9$, DIA $=111 \pm 4, \mathrm{DEA}=94 \pm 4$ and (ii) $\mathrm{AT}=98 \pm 8, \mathrm{DIA}=105 \pm 6, \mathrm{DEA}=96 \pm 4$. These results corroborate the accuracy, and demonstrate acceptable RSD, maximum value of $9.1 \%$ for AT. It suggests that the condition of extraction here employed is able to determine the total fraction of AT, DIA and DEA in this kind of soil, or at least the fraction with higher mobility. Nevertheless, this supposition has to be evaluated with caution, since no additional comparative experiments were performed. 
After that, a recovery study was made with different AT, DEA and DIA contents, according to the results shown in Table 3.

Table 3. Recovery results ( $n=3,95 \%$ confidence level) of atrazine (AT), deisopropylatrazine (DIA) and deethylatrazine (DEA). Initial contents of 500,2000 and $5000 \mu \mathrm{g} \mathrm{kg}^{-1}$ of each analyte

\begin{tabular}{lcccc}
\hline \multirow{2}{*}{ Analyte } & \multirow{2}{*}{ Depth / cm } & \multicolumn{3}{c}{ Recovery values / } \\
\cline { 3 - 5 } & $0-10$ & $83 \pm \mathrm{g} \mathrm{kg}^{-1}$ & $2000 \mu \mathrm{gg}^{-1}$ & $5000 \mu \mathrm{g} \mathrm{kg}^{-1}$ \\
\hline \multirow{3}{*}{ AT } & $10-30$ & $81 \pm 9$ & $104 \pm 9$ & $94 \pm 4$ \\
& $30-50$ & $81 \pm 8$ & $93 \pm 5$ & $96 \pm 13$ \\
\hline \multirow{3}{*}{ DIA } & $0-10$ & $78 \pm 7$ & $102 \pm 9$ & $98 \pm 11$ \\
& $10-30$ & $68 \pm 9$ & $98 \pm 16$ & $105 \pm 3$ \\
& $30-50$ & $64 \pm 7$ & $99 \pm 5$ & $96 \pm 15$ \\
\hline \multirow{2}{*}{ DEA } & $0-10$ & $67 \pm 7$ & $90 \pm 7$ & $98 \pm 5$ \\
& $10-30$ & $61 \pm 9$ & $94 \pm 5$ & $99 \pm 6$ \\
& $30-50$ & $64 \pm 3$ & $99 \pm 5$ & $100 \pm 10$ \\
\hline
\end{tabular}

An acceptable accuracy is shown in Table 3 for AT, DIA and DEA, and apparently no tendency of lower recovery was observed for the different depths for AT, DIA and DEA, as well as between the three analytes. On the other hand, the recovery results for the initial content of $500 \mu \mathrm{g} \mathrm{kg}^{-1}$ were systematically lower in comparison with the other values. Maybe this is a drawback related with the lower content, although the estimated LOQ value was $50 \mu \mathrm{g} \mathrm{kg}^{-1}$. A fitting precision also was verified, with a maximum RSD of $17.3 \%$ for AT, $0-10 \mathrm{~cm}$ at $2000 \mu \mathrm{g} \mathrm{kg}^{-1}$. Based on the best condition obtained according to the factorial design and the recovery results, it can be inferred that this method can be applied for the extraction of AT, DIA and DEA from soil samples, in contents between 500 and $5000 \mu \mathrm{g} \mathrm{kg}^{-1}$, at least for the soil with the physicochemical characteristics shown in Table 2. This method will be employed for the first time in a forthcoming study, aiming an evaluation of the atrazine behavior in the oxisol from the region of Pato Branco City (Southwest of Paraná State). The lowest dose of the active ingredient is $0.75 \mathrm{~kg} \mathrm{ha}^{-1}$ and the recommended doses are between 1.00 and $3.25 \mathrm{~kg} \mathrm{ha}^{-1},{ }^{1}$ and as a result, the AT content in soils is relatively high and this was the reason for the choice of the range from 500 to $5000 \mu \mathrm{g} \mathrm{kg}^{-1}$ in the present study.

As earlier described, all the experiments were carried out using $72 \mathrm{~h}$ for the dryness. Because of this short time for the AT interaction with the soil particles, an additional experiment was made using $2500 \mu \mathrm{g} \mathrm{kg}^{-1}$ of $\mathrm{AT}$, in order to verify the performance of the extraction method after higher contact times between AT with the soil sample, but under controlled conditions, with the sealed flasks in the dark at $4{ }^{\circ} \mathrm{C}$ under rest. The results are shown in Table 4.
Table 4. Results ( $n=3,95 \%$ confidence level) for atrazine (AT), deisopropylatrazine (DIA) and deethylatrazine (DEA) in the soil after 15, 30,45 and 60 days of contact time under controlled conditions. Initial AT content of $2500 \mu \mathrm{g} \mathrm{kg}^{-1}$

\begin{tabular}{lccccc}
\hline \multirow{2}{*}{ Analyte } & \multirow{2}{*}{ Depth / cm } & \multicolumn{4}{c}{ Results $/\left(\mu \mathrm{g} \mathrm{kg}^{-1}\right)$} \\
\cline { 3 - 6 } & $0-10$ & $2583 \pm 53$ & $2186 \pm 10$ & $1992 \pm 26$ & $1767 \pm 46$ \\
\multirow{4}{*}{ AT } & $10-30$ & $2353 \pm 57$ & $1969 \pm 10$ & $1825 \pm 21$ & $1545 \pm 20$ \\
& $30-50$ & $2233 \pm 36$ & $1472 \pm 13$ & $1469 \pm 34$ & $1287 \pm 19$ \\
\hline \multirow{4}{*}{ DIA } & $0-10$ & $81 \pm 2$ & $32 \pm 2^{\mathrm{a}}$ & $103 \pm 7$ & $94 \pm 6$ \\
& $10-30$ & $64 \pm 3$ & $29 \pm 1^{\mathrm{a}}$ & $93 \pm 9$ & $90 \pm 7$ \\
& $30-50$ & $83 \pm 1$ & $28 \pm 1^{\mathrm{a}}$ & $87 \pm 13$ & $97 \pm 3$ \\
\hline \multirow{4}{*}{ DEA } & $0-10$ & $58 \pm 3$ & $33 \pm 3^{\mathrm{a}}$ & $23 \pm 14^{\mathrm{a}}$ & $76 \pm 4$ \\
& $10-30$ & $40 \pm 10^{\mathrm{a}}$ & $29 \pm 2^{\mathrm{a}}$ & $\mathrm{nd}^{\mathrm{b}}$ & $68 \pm 10$ \\
& $30-50$ & $49 \pm 6^{\mathrm{a}}$ & $27 \pm 3^{\mathrm{a}}$ & $20 \pm 5^{\mathrm{a}}$ & $73 \pm 8$ \\
\hline
\end{tabular}

abelow the LOQ value $\left(50.0 \mu \mathrm{g} \mathrm{kg}^{-1}\right)$; ${ }^{\text {bnd }}=$ not detected.

According to Table 4, a decrease of 29, 38 and $48 \%$ in the AT initial content $\left(2500 \mu \mathrm{g} \mathrm{kg}^{-1}\right)$ was verified, between 15 and 60 days, for 0-10, 10-30 and 30-50 cm, respectively, although an anomalous value was verified for $0-10 \mathrm{~cm}$ (15 days). The decrease in the AT contents suggests a degradation process in this period. In fact, according to Kleinschmitt et al. ${ }^{30}$ a significant degradation process takes place in a short period of time (64 days), and between 65 and $70 \%$ of the applied atrazine in different soil samples may be considered as a bound fraction, but this was performed under room temperature. Nevertheless, in the experiments of the present study all the flasks were sealed, kept at $4{ }^{\circ} \mathrm{C}$ and in the absence of light, which are not propitious conditions for the degradation of atrazine. Indeed, low concentrations of the degradation products, DIA and DEA, were observed between 15 and 60 days that is indicative of the not significant AT degradation. In spite of this, Mahía et al., ${ }^{5}$ studying five different soil samples at $28^{\circ} \mathrm{C}$ in the darkness, verified an abrupt depletion of AT content for the most of soils after three weeks, as well as a great evolution of DIA content in the first week, with decreasing values after three weeks, with a constant content of hydroxyatrazine (HA) between 1 and 12 weeks. According to these authors, the first step of the AT metabolism is a chemical process of dechlorination with the formation of HA, followed by N-dealkylation and DIA formation. Thus, based on the AT and DIA attenuation, a possible mineralization process of these compounds may have taken place. The $\mathrm{pH}$ is an important parameter related to HA formation, being $\mathrm{pH}$ values lower than 6 , favorable for the hydrolysis of AT and the consequent arising of HA. ${ }^{2,17}$ This is a condition provided in the present study, since the samples presented $\mathrm{pH}$ values between 4.7 and 5.0 (Table 2). It is important to notice that the chromatograms 
of the blank analysis showed no peaks for AT, DEA and DIA (Figure 1). In addition, using longer chromatographic separations, no additional peaks were observed, indicating that no other degradation products were formed. The HA peak would be observed close to the peaks of DIA and DEA and before the AT peak, ${ }^{5,17,27}$ but this was not observed. HA has a strong interaction with soil particles with high sorption coefficient, $, 2,5$ and might be considered as a bound residue, ${ }^{3,8}$ requiring the use of more vigorous extraction processes. Furthermore, the solubility of HA in water is close to $7.0 \mathrm{mg} \mathrm{L}^{-1}$, that could minimize its extraction. Although the extraction was performed using acetonitrile, HA requires not only a lower polarity, but also an acidic medium in order to maximize its solubility as a protonated species, ${ }^{31}$ and for this reason, the appropriate dissolution of $\mathrm{HA}$ needs the use of $\mathrm{HCl}$ medium, even in the presence of organic solvents as methanol. ${ }^{27}$ Thus, based on the results and on the literature previously mentioned, it is indicative that a mineralization process occurred, regardless of the controlled conditions; or also the method was not effective for the HA extraction. It is important to inform, that HA was not studied in the present work, owing to its intense interaction with the soil particles, providing lower mobility in soils in comparison with AT, DEA and DIA, and as a result, HA presents low likelihood to contaminate groundwaters and surface waters. The more effective extraction methods were not investigated in this work, for instance PLE, ${ }^{1,22}$ that could provide the quantification of the bound fraction. Notwithstanding, the results here presented suggest that the method is suitable for the extraction of the more mobile fraction of AT, DIA and DEA, and possibly for other triazines, which is the most relevant fraction for environmental evaluations.

\section{Conclusions}

The proposed HPLC method was appropriate to quantify the analytes AT, DIA and DEA, providing short chromatographic separation, saving time and mobile phase with acceptable resolution. Based on the comparative results between SE and UE, the former demonstrated to be more satisfactory, at least for the oxisol sample studied at this time, suggesting that a more vigorous irradiation power would be required for UE. The simple SE method showed attractive characteristics, making use of $9.0 \mathrm{~mL}$ of acetonitrile for each sample, without the use of expensive equipments. It is important to notice, that the factorial design was an important tool to achieve the best conditions of extraction for AT, DIA and DEA from oxisol, especially the definition of the lower contact time of $30 \mathrm{~min}$. A suitable LOQ value was achieved, with appropriate recovery values for the three analytes in the three depths, and the results suggest a partial AT degradation in a short period of time. According to the present study, one can conclude that this method can be used for extraction of AT, DEA and DIA in oxisol samples, or even for soils with similar physicochemical characteristics, aiming at the quantification of the fraction potentially able to contaminate groundwaters and surface waters.

\section{Acknowledgments}

The authors are grateful to Conselho Nacional de Desenvolvimento Científico e Tecnológico (CNPq) for the financial support. M. F. A. thanks Coordenação de Aperfeiçoamento de Pessoal de Nível Superior (CAPES) for the fellowships, and Universidade Tecnológica Federal do Paraná (UTFPR), Campus de Pato Branco, for the physicochemical analyses of the soil and the opportunity to carry out the current study, as a part of the doctorate thesis.

\section{References}

1. Martinazzo, R.; Jablonowski, N. D.; Hamacher, G.; Dick, D. P.; Burael, P.; J. Agric. Food Chem. 2010, 58, 7864.

2. Abate, G.; Penteado, J. C.; Cuzzi, J. D.; Vitti, G. C.; Lichtig, J.; Masini, J. C.; J. Agric. Food Chem. 2004, 52, 6747.

3. Jablonowski, N. D.; Koeppchen, S.; Hofmann, D.; Schaeffer, A.; Burael, P.; J. Agric. Food Chem. 2008, 56, 9548.

4. Dick, D. P.; Martinazzo, R.; Knicker, H.; Almeida, P. S. G.; Quim. Nova 2010, 33, 14.

5. Mahía, J.; Martín, A.; Diaz-Raviña, M.; Environ. Geochem. Health 2008, 30, 147.

6. Potter, T. L.; Bosch, D. D.; Joo, H.; Schaffer, B.; MunozCarpena, R.; J. Environ. Qual. 2007, 36, 1301.

7. Smith, G. A.; Pepich, B. V.; Munch, D. J.; J. Chromatogr., A 2008, 1202, 138.

8. Kookana, R.; Holz, G.; Barnes, C.; Bubb, K.; Fremlin, R.; Boardman, B.; J. Environ. Manage. 2010, 91, 2649.

9. Vryzas, Z.; Papadakis, E. N.; Papadopoulou-Mourkidou, E.; Water Res. 2012, 46, 1979.

10. Stackelberg, P. E.; Barbash, J. E.; Gilliom, R. J.; Stone, W. W.; Wolock, D. M.; J. Environ. Qual. 2012, 41, 479.

11. Celano, G.; Šmejkalov, D.; Spaccini, R.; Piccolo, A.; J. Agric. Food Chem. 2008, 56, 7360.

12. Lesueur, C.; Gartner, M.; Mentler, A.; Fuerhacker, M.; Talanta 2008, 75, 284.

13. Amalric, L.; Mouvet, C.; Pichon, V.; Bristeau, S.; J. Chromatogr., A 2008, 1206, 95.

14. Wu, Q.; Li, Z.; Wu, C.; Wang, C.; Wang, Z.; Microchim. Acta 2010, 170, 59.

15. Silva, V. M.; Costa, W. F.; Visentainer, J. V.; Souza, N. E.; Oliveira, C. C.; J. Braz. Chem. Soc. 2010, 21, 1045. 
16. Shah, J.; Jan, M. R.; Ara, B.; Shehzad, F.; Environ. Monit. Assess. 2011, 178, 111.

17. Barchanska, H.; Rusek, M.; Szatkowska, A.; Environ. Monit. Assess. 2012, 184, 321.

18. Dean, J. R.; Wade, G.; Barnabas, I. J.; J. Chromatogr., A 1996, 733, 295.

19. Delgado-Moreno, L.; Peña, A.; Mingorance, M. D.; J. Hazard. Mater. 2009, 162, 1121

20. Gonçalves, C.; Carvalho, J. J.; Azenha, M. A.; Alpendurada, M. F.; J. Chromatogr., A 2006, 1110, 6.

21. Mohammadi, A.; Ameli, A.; Alizadeh, N.; Talanta 2009, 78, 1107.

22. Jablonowski, N. D.; Hamacher, G.; Martinazzo, R.; Langen, U.; Köppchen, S.; Hofmann, Burael, P.; J. Agric. Food Chem. 2010, 58, 12869.

23. Andreu, V.; Picó, Y.; TrAC, Trends Anal. Chem. 2004, 23, 772.

24. Site, A. D.; J. Phys. Chem. Ref. Data 2001, 30, 187.
25. Loos, R.; Niessner, R.; J. Chromatogr., A 1999, 835, 217.

26. Balena, S. P.; Messerchmidt, I.; Tomazoni, J. C.; Guimarães, E.; Pereira, B. F.; Ponzoni, F. J.; Blum, W. E. H.; Mangrich, A. S.; J. Braz. Chem. Soc. 2011, 22, 1788.

27. Zarpon, L.; Abate, G.; dos Santos, L. B. O.; Masini, J. C.; Anal. Chim. Acta 2006, 579, 81.

28. Santos, H. M.; Capelo, J. L.; Talanta 2007, 73, 795.

29. Tadeo, J. L.; Sánchez-Brunette, C.; Albero, B.; García-Valcárcel, A. I.; J. Chromatogr., A 2010, 1217, 2415.

30. Kleinschmitt, A. R. B.; Dick, D. P.; Selbach, P. A.; dos Santos, M.; Ciência Rural 2006, 36, 1794.

31. Vermeulen, N. M. J.; Apostolides, Z.; Potigieter, D. J. J.; Nel, P. C.; Smit, N. S. H.; J. Chromatogr., A 1982, 240, 247.

Submitted: August 3, 2012 Published online: March 15, 2013 